\title{
Managing botanic garden collections of high conservation value
}

\author{
Martin F. Gardner ${ }^{1}$
}

\section{Abstract}

The author has spent 30 years coordinating the International Conifer Conservation Programme (ICCP), based at the Royal Botanic Garden Edinburgh, and uses this significant milestone to reflect on some important aspects of managing genetic resources in plants of conservation concern. Much of the information in this article is derived from experience and observations made over this time. The main driver of the ex situ component of the ICCP has been to develop robust protocols for broadening the genetic base of threatened conifers and a range of conservation-dependent Chilean woody plants in cultivation. This is achieved using well-documented material of known wild origin distributed through a dedicated network of 'safe sites'. Descriptions of actions taken to conserve Fitzroya cupressoides and Amentotaxus argotaenia are given as examples of threatened species for which collection and cultivation of a breadth of genetic material has enabled meaningful conservation. The conservation strategy to increase the range of genetic material in cultivation sometimes involves using novel methods including conservation hedges. The great challenge facing all managers of botanical collections is to develop programmes that integrate ex situ and in situ conservation. The biggest contribution collection managers and growers can make to the conservation of species is to maximise the value of collections in their care, and actions that achieve this are listed.

\section{Introduction}

Over a period of 30 years, the International Conifer Conservation Programme (ICCP) has been developing and refining protocols to manage conservation collections of high scientific value. The ICCP (then known as the Conifer Conservation Programme) was launched in 1991, the brainchild of Dr Chris Page, who led on conifer and fern research at the Royal Botanic Garden Edinburgh (RBGE) for more than 20 years. One of the main drivers of the Programme is the high number of threatened conifer species, today standing at 211 - 34 per cent of known conifer species worldwide (RBGE, 2016). Before the launch of the ICCP, aspects had already been implemented by developing the idea of an outreach programme for the cultivation of threatened conifers (Page, 1994). Sites included several Cornish gardens and the extensive campus at Exeter University (UK), originally laid out by the famous nursery family of Veitch. These experimental sites were the recipients of collections made by Page during years of fieldwork in North America, Japan and Taiwan. However, it was not until 1991 that the outreach programme, which is now referred to as a network of 'safe sites', began to develop in earnest. This strategic distribution of conifers is unprecedented and is the most ambitious programme of its type ever undertaken in the UK and Ireland.

\footnotetext{
${ }^{1}$ Martin Gardner is Coordinator of the International Conifer Conservation Programme at Royal Botanic Garden Edinburgh. Address: 20A Inverleith Row, Edinburgh, EH3 5LR, UK. 
Another method of conserving a wide range of genetic material is in hedges where the growth habit of a species is suitable for such cultivation. The application of this method is described in detail in Gardner et al. (2019) and the benefits of this method are outlined here.

The aim of a programme such as the ICCP is to conserve all threatened species within its remit. This is a long-term and resourceintensive process, and the description of how Fitzroya cupressoides and Amentotaxus argotaenia are now in a better position to be conserved in situ below provides an insight into the sustained effort required to achieve meaningful results. In some cases, the plants need to be looked after ex situ for many years before the time is right to integrate in situ conservation, often when the individuals who started the process are no longer involved.

Botanic garden collections can provide the necessary long-term continuous care required, at the same time as offering educational and amenity value for their visitors and other users. The display of Chilean plants at RBGE is an example of a well-documented wild origin collection. At the time of writing (2021), the mature plants are under a level of threat due to the need to refurbish facilities where they are planted. Careful horticultural management will ensure the persistence of the collection for use in future conservation projects. Horticulturists and curators must be mindful that the work they do assessing and recording the cultivation requirements is an essential resource which they and others who come after them can use to restore and conserve these species in their place of origin - the end point of the conservationist's aim.

\section{Network of safe sites}

Today the ICCP works with over 200 different locations (Fig. 1). These include about 145 sites (some sites have multiple locations) comprising 14,000 individual conifers, which represent 155 conifer taxa of which 95 are conservation dependent. ${ }^{2}$

The three most important qualities a site needs to have for ICCP to work with it are:

- a relatively large area of land

- a relatively secure future to maintain consistent care and access to the plants

- $\quad$ sufficient resources to support establishment, installation of protection and monitoring

Sourcing the plant material for ex situ conservation is carried out in collaboration with in-country partners and conducted in a manner that is careful to ensure wild populations are not put at additional risk. The majority of the collections are in the form of seed and, where possible, each field number represents seed collected from an individual mother tree. Broadening the genetic base of cultivated threatened conifer species is at the core of the ICCP's remit, and as far as is possible activities are guided by population genetic studies (Allnutt et al., 1998; Allnutt et al., 1999). Therefore, adopting sites with relatively large areas of land has been a priority. To this end, a successful partnership has been developed with Forestry and Land Scotland (formerly the Forestry Commission) and the Perth \& Kinross Countryside Trust (PKCT) with whom the ICCP has collaborated to develop two important initiatives: the Perthshire Conifer Conservation Programme (PCCP) and the National Tree Collections of Scotland (NTCS) (Perth \& Kinross Countryside Trust, 2020a \& b). Many of the

${ }^{2}$ This term is applied to a species for which measures are required to prevent it from being threatened with extinction. A definition is given here: https://wikimili.com/ en/IUCN_Red_List_conservation_dependent_species 


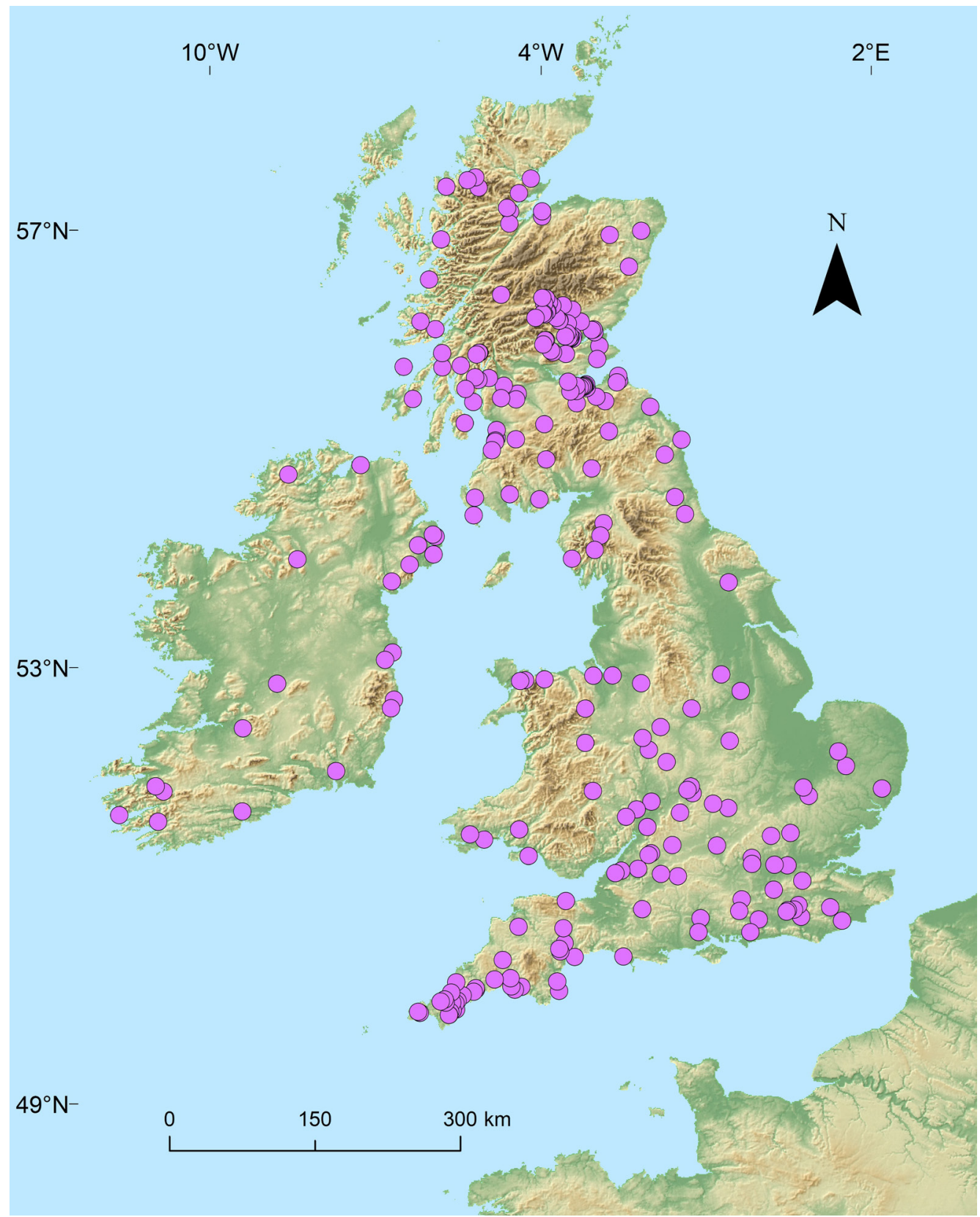

Fig. 1 Map showing the distribution of ICCP safe sites, as purple dots, in the UK and Ireland. Map drawn by Vanezza Morales.

sites in this partnership have the capacity to accommodate relatively large numbers of a single species. For example, 235 Picea omorika have been planted over three sites: in Craigvinean Forest (70), the grounds of
Dunkeld Hilton Hotel (120) and the woodland park of Kinnoull Hill (45).

Parks and gardens that are easily accessible and free to enter, with regular footfall of members of the public, offer an 
ideal opportunity to establish threatened species and install innovative interpretation to increase public awareness of conifer conservation. Such installations have been realised in several places, including Benmore Botanic Garden in Argyll and the Lodge Park in North Berwick, East Lothian - both in Scotland. An important criterion used for adopting 'safe sites' is having a degree of longevity of future tenure together with a high standard of horticultural expertise. Even with these conditions in place, it is not always apparent that a site is going to be able to fulfil all the requirements for the long term. One key ingredient to a successful site is the continuity of ownership and curatorial staff. Traditionally, head gardeners remained in post for a long time, sometimes for their entire career, but this is often no longer the case - understandably so - and the lack of continuity in leadership can present problems for managing plant collections.

The initial enthusiastic assurances made by site owners to take care of the conifers that form part of an international campaign to safeguard their long-term future sometimes fail to materialise. The main cause can be the lack of willingness to incur the costs to protect conifers once they are in the ground: robust rabbit- and deer-proof fencing is essential. The diligent curation of plant material is of the utmost importance. Certainly, the loss of labels will greatly impact on the conservation value of threatened plant collections. When multiple individuals of a single species are allocated to a site, only one accession number is used, helping to guard against any loss of information. A further mitigating strategy against the loss of label data is recording tree locations by using a Geographic Information System (GIS), and since 2018 over 1,000 trees in Scottish sites have been recorded in this manner.
The most challenging aspect of ex situ conservation is not always obtaining the propagation material, although this often requires negotiation of very precarious surroundings; it is planting and aftercare, which invariably present more complex problems. The successful establishment of conifers (or indeed any plant) can be compromised by factors that impair growth or kill the tree, including:

- damage caused by grazing animals or by engine-powered tools

- smothering from competing invasive vegetation

- $\quad$ girdling caused by label ties

- $\quad$ shade from neighbouring trees

In the author's experience, one of the most common causes of death is mechanical damage as a result of the careless use of lawnmowers and strimmers. However, the onus remains on the ICCP to have continuous contact with sites, with regular visits to monitor the conifers and to look at any emerging problems and new opportunities. This has not always been possible because of the logistical challenges of servicing an ever-expanding network.

\section{Conservation hedges}

One of the daunting challenges botanic gardens face is the conservation of genetic resources through the cultivation of plants. Often, because of limited space, woody species are represented by a single genotype that is invariably replicated in other gardens. The 'numbers game' botanic garden managers sometimes find themselves drawn into, whereby success is measured in terms of the number of species and accessions growing in a garden, needs finer scrutiny. Collection managers should be concerned 
with the critical numbers of genotypes and provenances for each species for successful conservation. This level of detail has been integral to the operation of the ICCP. A novel way in which to accommodate relatively large numbers of genotypes in a limited space is in a hedge (Gardner et al., 2019). RBGE's Edinburgh Garden is no longer surrounded by a holly hedge of a single clone with little scientific value, as it was for many years. Instead, the Garden boundary now comprises 2,000 plants of Taxus baccata packed with biodiversity from 17 countries and 37 heritage trees occurring across the British Isles and Europe (Fig. 2).

This model, where hedges are used for storing genetic material, has also been implemented for other species, including Saxegothaea conspicua, which now surrounds (on three sides) the Botanic Cottage at RBGE's Edinburgh Garden. The best practice when considering material for conservation hedges is to choose a single provenance. If mixed provenances are used then extra care in labelling is required. The current system used for keeping track of genotypes is to plant them in order of accession number and plot these on a database. Annual stocktakes are then carried out to identify any plant losses. The most widely used species for conservation hedges has been the Chilean endemic conifer Prumnopitys andina. Over 600 plants representing unique genotypes have been planted in conservation hedges in four ICCP sites. In March 2021, 100 seedlings were shipped to Inverewe Gardens in Wester Ross, Scotland, for a boundary hedge between the garden and the car park. The plants at Inverewe are limited to seedlings germinated from seed that was collected from seven trees in the San Fabian Valley in Chile's Maule Region. This species is notoriously difficult to propagate from seed (Gardner et al., 2017); furthermore, experience indicates that seed viability from this population is relatively poor. One thousand old-growth trees in the San Fabian Valley are now in danger of being engulfed by a new hydroelectric scheme that will eventually flood the valley. While this is an effective ex situ model for storing genetic material that would otherwise have been lost in the wild, it is no substitute for in situ conservation. The messages supporting ex situ conservation should be well thought out and counter misguided reasoning which is sometimes posed by those exploiting natural resources. One personal exchange with someone involved in a logging operation in Chile resulted in the statement 'Tell me when you have harvested sufficient seed for growing in the UK and then I can cut the trees down.'

\section{Integrating ex situ and in situ conservation - Fitzroya cupressoides}

One example of how the ICCP has achieved integration of ex situ and in situ conservation is through research of Fitzroya cupressoides. This extraordinary conifer is endemic to southern Argentina and Chile (Fig. 3), where it has suffered more than three centuries of over-exploitation due to its highly prized wood. Research carried out by the ICCP (Allnutt et al., 1998) on cultivated trees of Fitzroya in the British Isles discovered that there was only a single female clone in cultivation. It is thought the clone originated from William Lobb's introduction, collected from Chile in 1849. Mindful that a single clone is of little use as a potential resource for restoring depleted native populations, the ICCP made a concerted effort to broaden the genetic base of plants in cultivation. Today, as a result of sampling seed and 


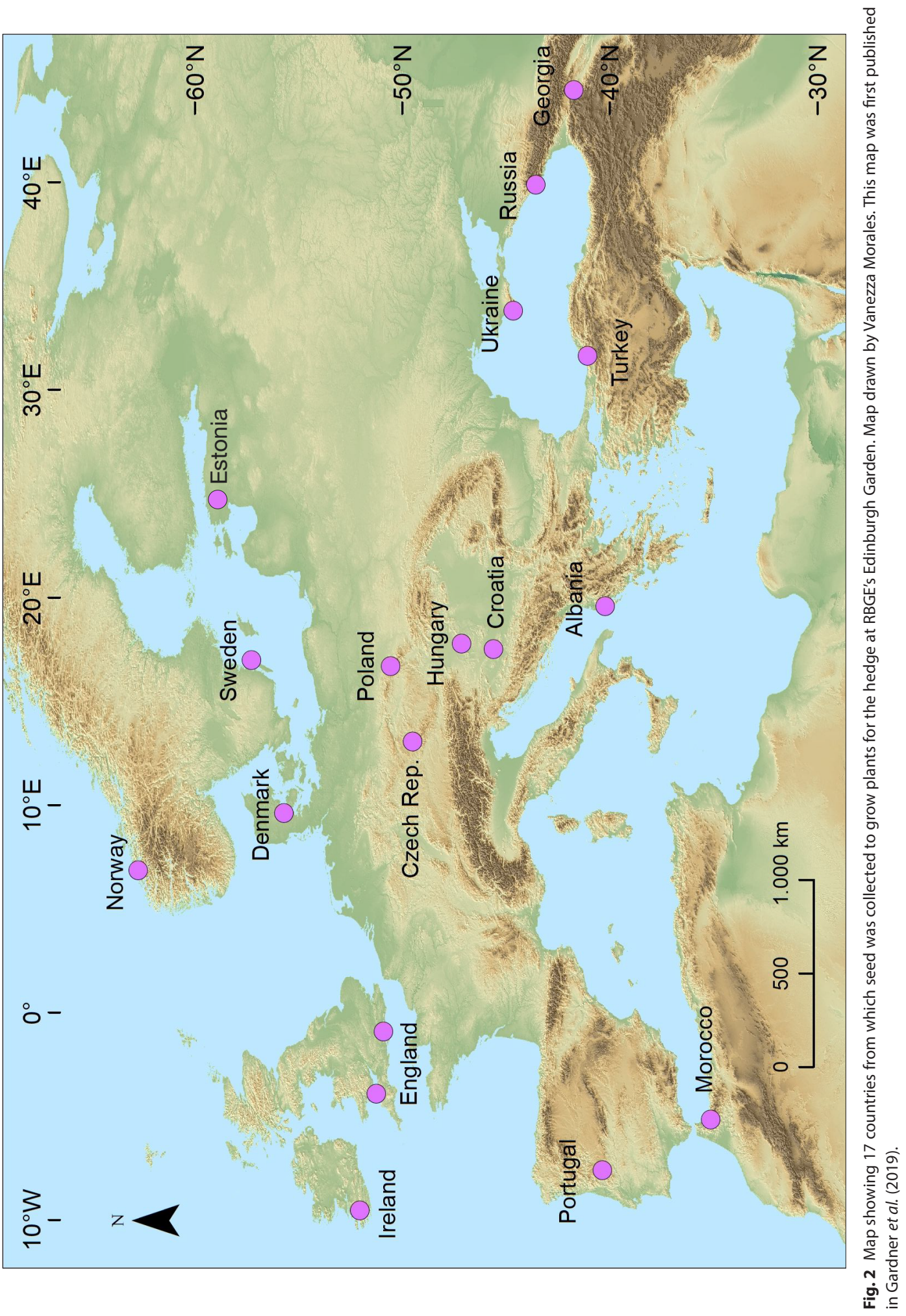




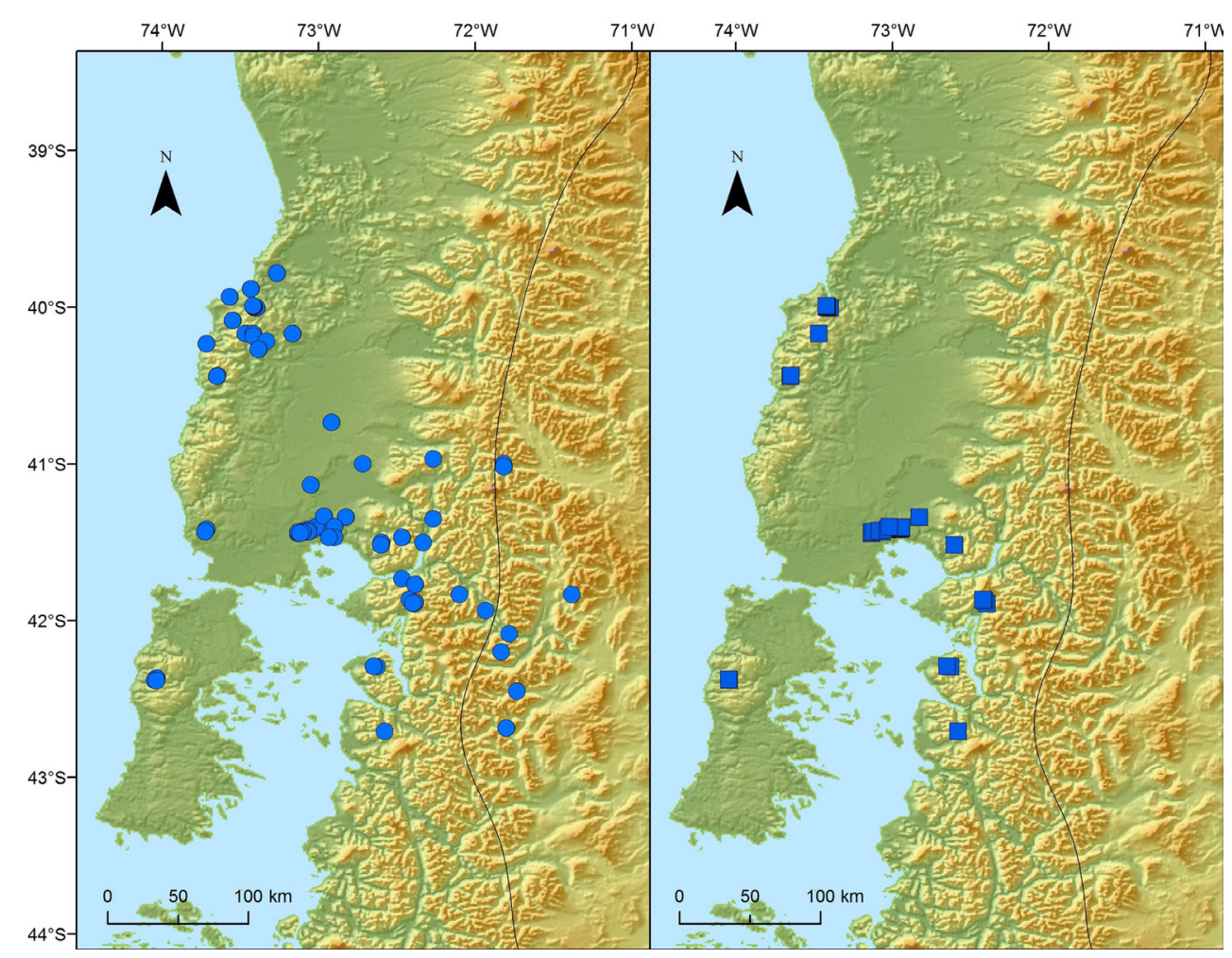

Fig. 3 Maps of Los Ríos and Los Lagos Regions, Chile, where Fitzroya cupressoides occurs in the wild. Left: Blue dots show the distribution of the species where plants have been recorded. Right: Blue squares indicate the locations from which ICCP collections have been made. Maps drawn by Vanezza Morales.

cuttings from across the natural range of Fitzroya, and guided by population genetics (Allnutt et al., 1998; Allnutt et al., 1999), the ICCP has introduced over 100 genotypes (both male and female) and distributed these through a network of 60 sites throughout the British Isles (Fig. 4). Although no research has been carried out on the genetic integrity of these additional genotypes, it can be assumed there has been a relative increase in the genetic diversity of trees in cultivation.

Importantly, the sampling strategy is guided by the molecular research carried out on Fitzroya in Argentina and Chile which identified unique populations that should be given conservation priority (Alnutt et al., 1999). This research has now led to a restoration programme of the severely depleted Fitzroya forests in Chile's Central Depression just north of Puerto Montt. Sampling from across the natural population is an ongoing process and has been hindered by the bureaucratic challenges of CITES permit processing to the extent that when a permit is eventually granted the propagation material has already perished.

\section{Repatriation of Amentotaxus argotaenia}

In 1976, Chris Page visited the New Territories of Hong Kong in order to research native conifers and ferns. His long-term ambition was to botanise the Tai Mo Shan, the highest peak of the islands with an elevation of $957 \mathrm{~m}$. Here the focus of attention was the enigmatic Amentotaxus argotaenia, which 


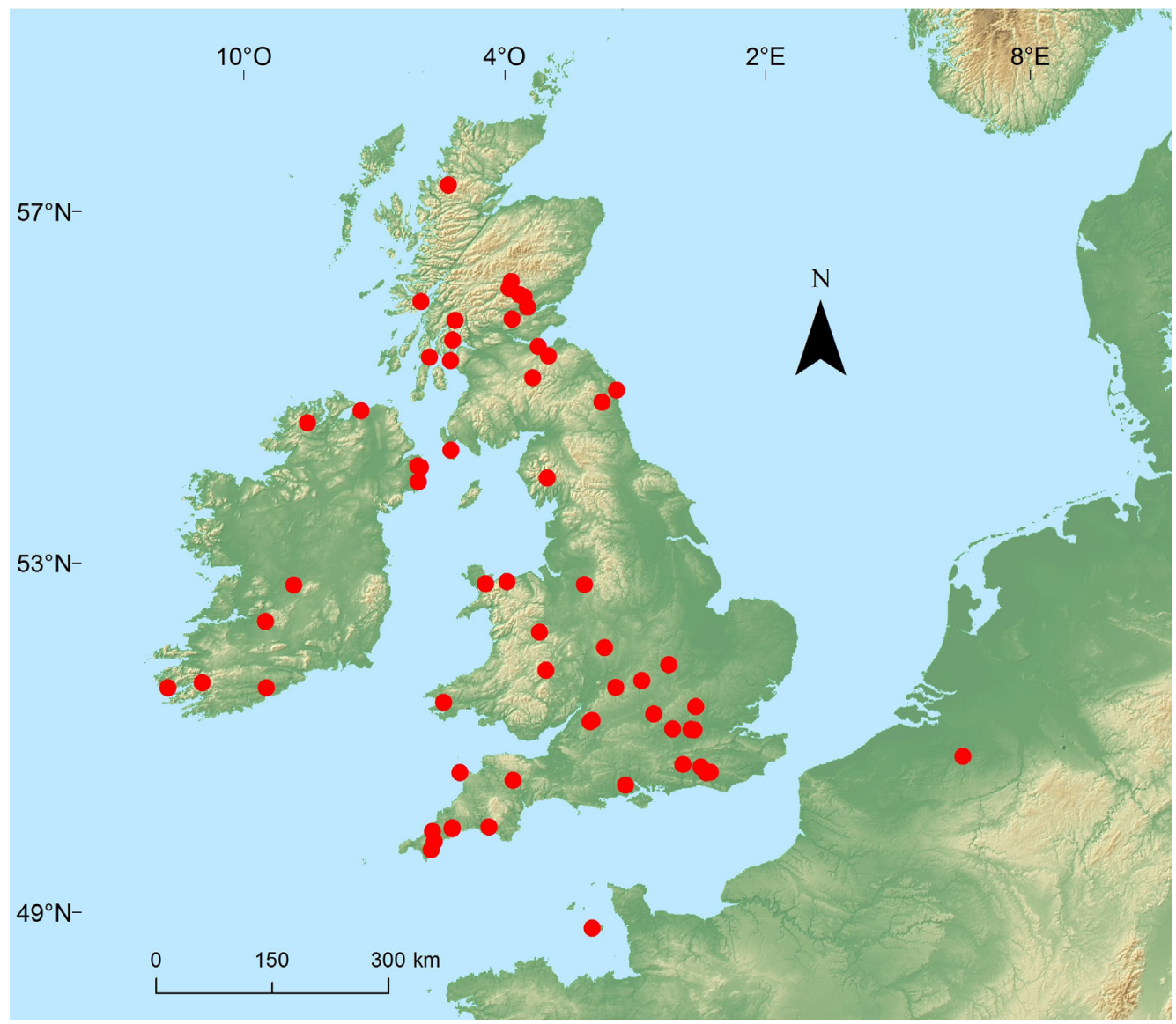

Fig. 4 Map showing ICCP safe sites where Fitzroya cupressoides (red dots) have been planted. The provenance and genotype of the plants are documented and stored with the plants on site. Map drawn by Vanezza Morales.

hitherto very few western botanists had observed in the wild. I clearly remember reading a letter sent by Page that year when I was a student of horticulture at RBGE. It was posted on the library noticeboard and reported the great excitement of finding Amentotaxus in Hong Kong. This marked one of the seminal moments that influenced me to follow a career in plant discovery and conservation. This very distinctive conifer, with two bright white, longitudinal bands beneath its lance-shaped leaves and its fleshy, strawberry-red, barrel-shaped seed cones, makes it very different from most other conifer species (Fig. 5). It is a very unusual member of the yew family with a distribution

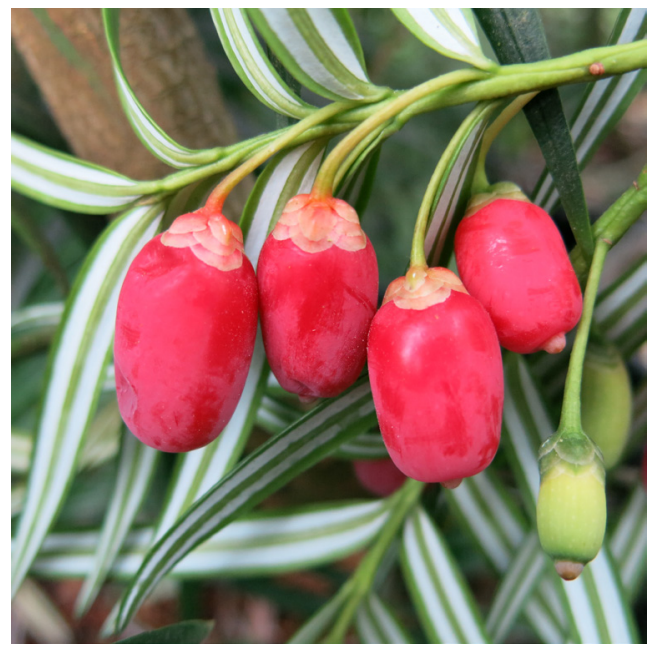

Fig. 5 The distinctive fruits of Amentotaxus argotaenia. Photo: Martin Gardner. 
across China and into Laos PDR and southern Vietnam. In Hong Kong, it is restricted to a few small populations. In fact, the population Chris Page saw comprised a single, female individual from which he collected cuttings that were sent back to RBGE, where they were successfully propagated.

Having discovered that the plants of Amentotaxus argotaenia cultivated by RBGE had been collected from Hong Kong, Craig Williams, the Senior Curator of Kadoorie Farm \& Botanic Garden in Hong Kong, contacted RBGE in 2017. There was a very good reason for obtaining material from the plants in Edinburgh: it was feared that the wild plants in Hong Kong could become victim to the looper moth (Milionia zonea) (Kendrick, 2017). The recent arrival to the islands of these highly colourful caterpillars has caused great concern due to their ability to defoliate the other conifer species growing in the botanic garden. A similar attack on the remaining small populations of $A$. argotaenia could have serious consequences.

Drawing on the expertise of Andy Ensoll, a Senior Horticulturist at RBGE who has developed the necessary skills to propagate Amentotaxus, 30 cuttings were rooted and grown on for about 18 months. Rigorous biosecurity checks were carried out by Scottish Government officials from Science \& Advice for Scottish Agriculture before a phytosanitary certificate was issued. The importing authorities in Hong Kong carried out similar procedures. Once the cuttings have been grown on to a suitable size, they will be used in ecological restoration programmes in Hong Kong and, together with other genotypes from Hong Kong, will help establish seed orchards for the species. In the meantime, suitable measures need to be taken in order to prevent any future damage from the looper moth.
Crucially, botanic gardens are not ephemeral organisations. They are here for the long haul, and they have to be because they are necessarily at the forefront of conservation, and conservation requires long-term solutions. They need to be effective repositories for genetic resources and therefore guarding against species extinction. In the case of Amentotaxus argotaenia, plants were kept alive for 43 years accompanied by relevant field data, and during their time in cultivation propagation protocols were established. Certainly for woody plants, this is the standard botanic gardens must attain for all plants being held in living collections. We must be poised ready for the ultimate contribution, which is to return plants back into their native habitats to support in situ conservation activities.

\section{Chilean conservation collections}

The planned new glasshouse complex and the refurbishment of the existing glasshouses at RBGE's Edinburgh Garden is one of RBGE's biggest infrastructure projects in its 350-year history and will have a significant impact on some important conservation collections in 2021. These include those on the Chilean Terrace located between the main Front Glasshouse Range and the Research Glasshouses. This entire collection will be temporarily relocated to the RBGE Nursery until the building work is complete, after which the plants are to be replanted in the same site. This level of disturbance will put at risk the survival of these plant collections that have been painstakingly collected and assiduously attended to in cultivation.

The collection of threatened Chilean plants formed part of a Darwin Initiative for the Survival of Species project in 2002-2005. The project surveyed a range of threatened plant species from south and central Chile. 
An important output was the publication of Plantas Amenazadas del Centro-Sur de Chile (Hechenleitner et al., 2005) which provides details of the distribution, conservation and propagation of 48 threatened species. RBGE's Chilean collection of over 40 species covers a relatively small area of about 0.25 ha but, importantly, it accommodates 18 threatened species. In fact, this area has the highest concentration of threatened plants growing anywhere outside at RBGE and it mirrors a similar collection established at the Arboretum of the University of Valdivia in Chile (Hechenleitner, 2005).

As an insurance policy against loss, many of these plants have been shared with other botanic gardens and collection holders within the UK using the ICCP's network of 'safe sites'. The largest subset of this material resides at Nymans Garden in West Sussex. Duplication of high-value conservation collections is important as long as in-country agreements for use of the material are adhered to. Many of the plants in the collection are new to cultivation, including Acrisione cymosa (Fig. 6), A. denticulata, Berberis negeriana (Fig. 7) and the members of Myrtaceae: Legrandia concinna (Fig. 8), Myrceugenia colchaguensis, M. lanceolata, M. leptospermoides (Fig. 9) and M. planipes. Valdivia gayana, a remarkable threatened member of the Escalloniaceae, has also been a focus of research (Fig. 10). Its habitat is on deeply shaded rocky ledges in Nothofagusdominated forests close to Valdivia. In the best-known location, near the fishing town of Corral, it grows on the walls of a deep coastal cave. At RBGE plants are grown under glass due to its demanding cultivation requirements. Horticultural techniques, developed for the successful cultivation of this species in which the watering regime is crucial, have been carefully documented and published (Ensoll et al., 2014). It cannot be overstated just how important it is for horticulturists to undertake this type of research and publish the results for the benefit of restoration programmes.

\section{Poised for the ultimate contribution}

Whenever I see a compost heap, it reminds me of a very thought-provoking essay by Quentin Cronk (2001), entitled 'Botanic gardens: a river of biodiversity'. This probing piece, which poses a number of questions about the worth of botanic gardens for ex situ conservation, contains two sentences that resonate: 'High levels of biodiversity are the result of an equilibrium between new accessions and losses, suspended between the plant-hunting expeditions on the one hand, and the compost heap on the other. The message for botanic gardens (and one that is not yet fully appreciated) is that collection managers do not manage "collections", they manage "biodiversity throughput" by controlling a vast river of germplasm through conduits and sluices until it is lost to the ocean of the compost heap'.

Before germplasm reaches the compost heap, I implore collection managers to systematically exploit the resource by 'squeezing' every unit of data from it. In doing so some of the following could be undertaken:

- Ensure the name is correct

- Extract and store DNA

- Take voucher herbarium material in both flower and fruit

- Use material for educational and research purposes

- Use the plants in a programme integrating ex situ and in situ conservation 


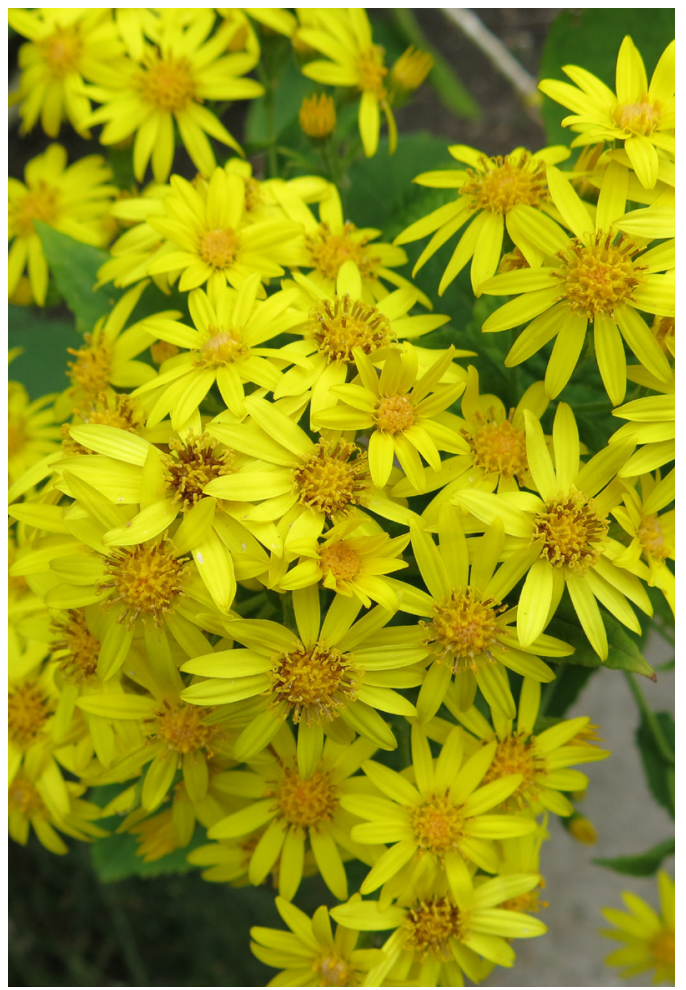

Fig. 6 Acrisione cymosa. Photo: Martin Gardner.

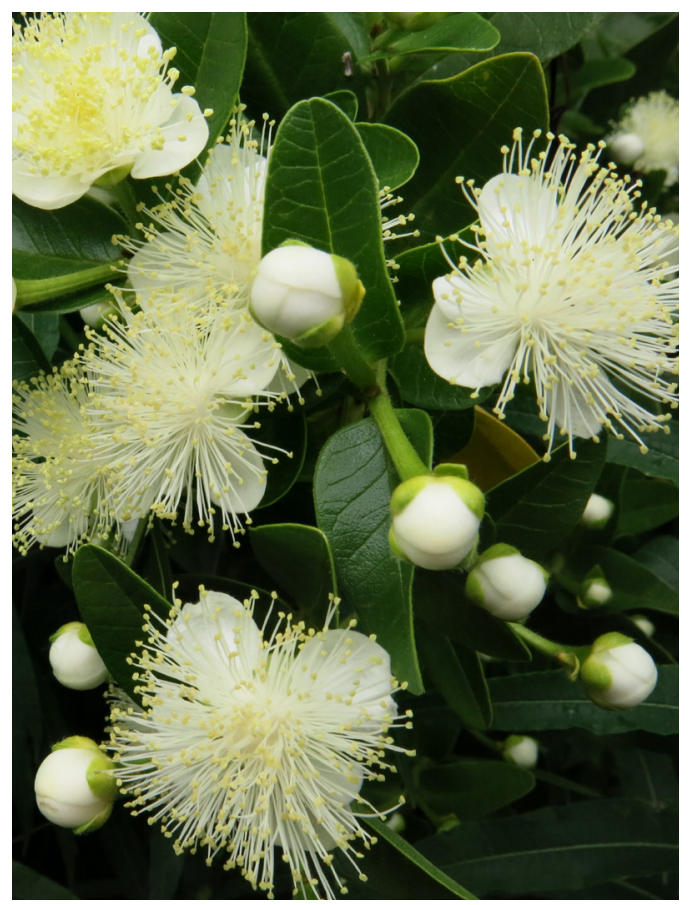

Fig. 8 Legrandia concinna. Photo: Martin Gardner.

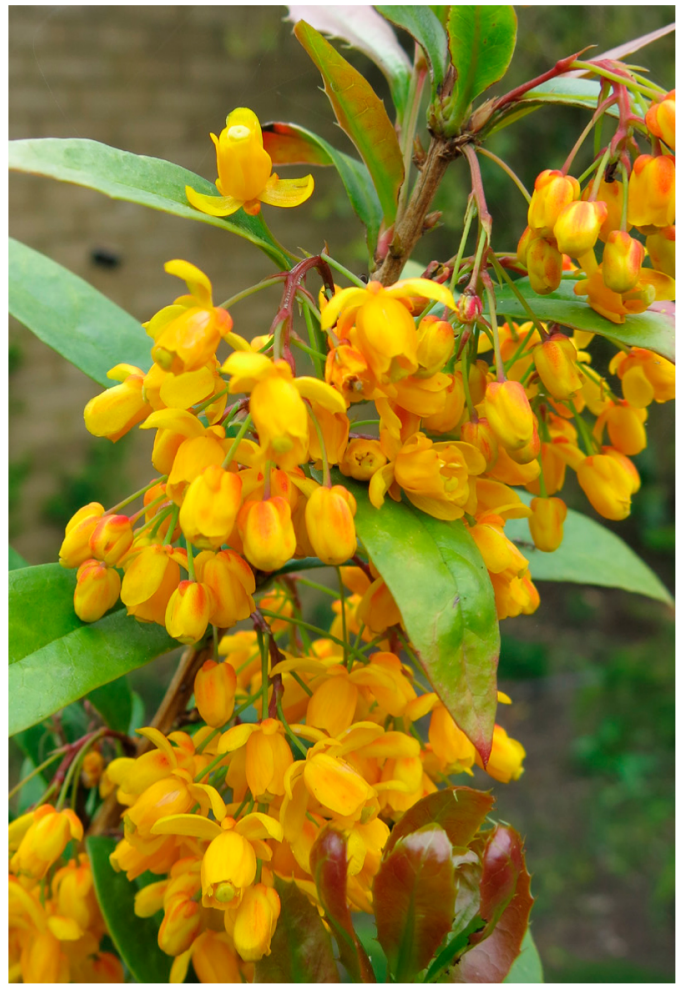

Fig. 7 Berberis negeriana. Photo: Martin Gardner.

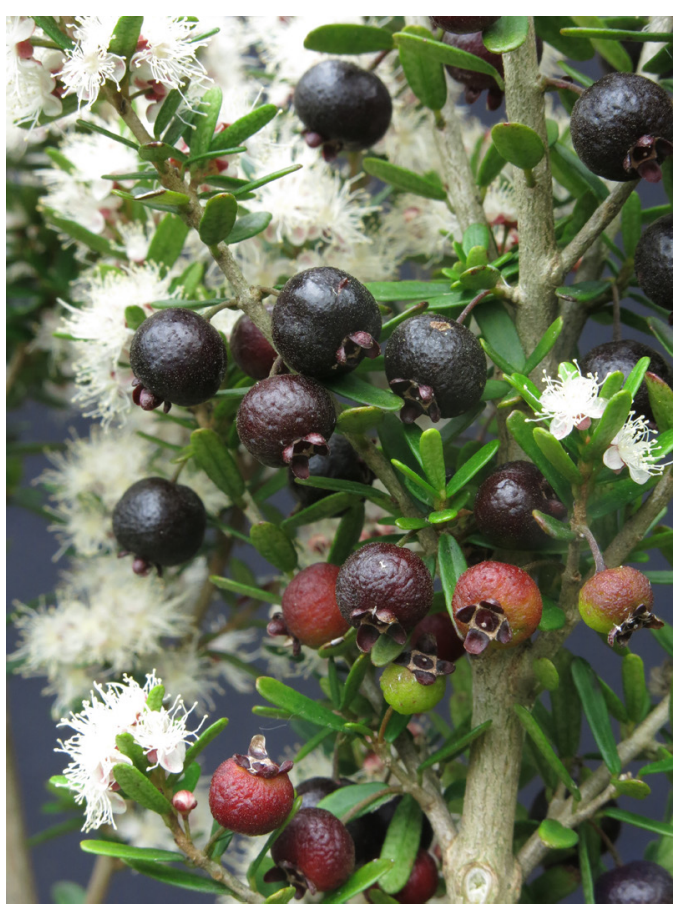

Fig. 9 Myrceugenia leptospermoides. Photo: Martin Gardner. 


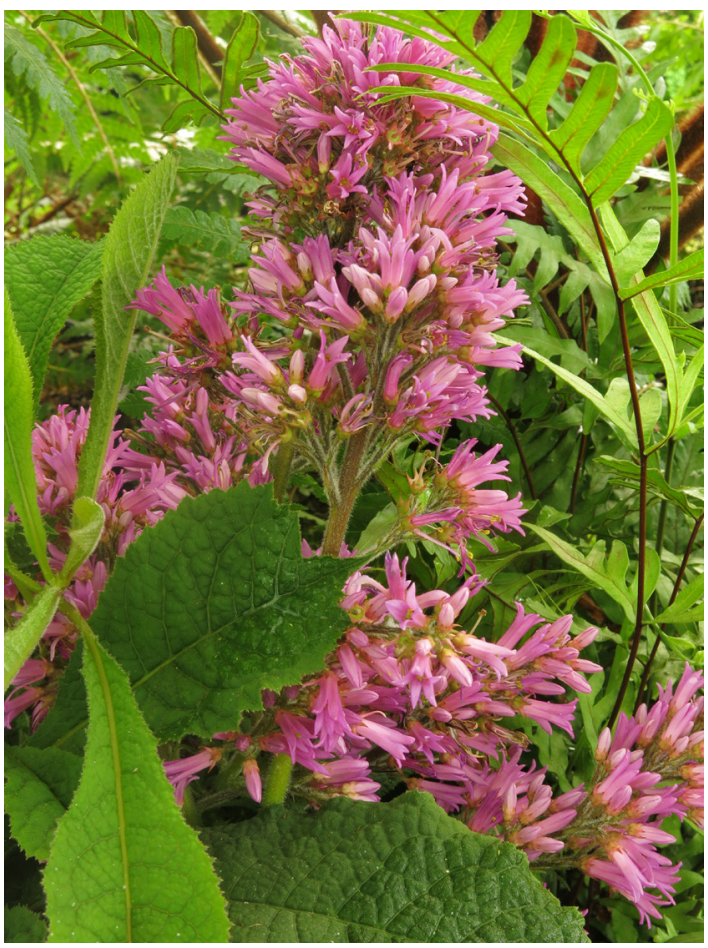

Fig. 10 Valdivia gayana. Photo: Martin Gardner.

Botanic gardens have an underlying responsibility to make sure the plants they grow are suitable for inclusion in conservation programmes. The return of Amentotaxus argotaenia to Hong Kong was significant: with the unprecedented erosion of genetic material in natural habitats, similar requests for the repatriation of plant species cultivated in botanic gardens will surely become increasingly common. With this in mind, we need to be poised for this ultimate contribution. We need to be ready with the detailed collecting records that are the prerequisite for meaningful repatriation; we need to be armed with the propagation protocols that are crucial for restoring depleted habitats. It is horticulturists, working in tandem with other professionals with related skills, who are at the forefront of helping to save our planet and making sure that we are indeed poised and ready for the ultimate contribution of repatriation of genetic material.

\section{References}

ALLNUTT, T., NEWTON, A.C., LARA, A., PREMOLI, A., ARMESTO, J., VERGARA, R. \& GARDNER, M.F. (1999). Genetic variation in Fitzroya cupressoides (alerce), a threatened South American conifer. Journal of Molecular Ecology, 8(6): 975-987. doi: https://doi. org/10.1046/j.1365-294x.1999.00650.x

ALLNUTT, T., THOMAS, P., NEWTON, A.C. \& GARDNER, M.F. (1998). Genetic variation in Fitzroya cupressoides cultivated in the British Isles, assessed using RAPDs. Edinburgh Journal of Botany, 55(3): 329-341. doi: https://doi.org/10.1017/ S096042860000322X

CRONK, Q. (2001). Botanic gardens: a river of biodiversity. In: GOVIER, R. et al. (eds), Catalogue of Plants 2001. RBGE, Edinburgh, pp. Ivi-Ixi.

ENSOLL, A., HUGHES, K. \& GARDNER, M. (2014). Cultivation of Valdivia gayana J. Rémy - a little-known herb from southern Chile. Sibbaldia, 12: 57-65. doi: https://doi.org/10.24823/sibbaldia.2014.23

GARDNER, M., CHRISTIAN, T., HINCHLIFFE, W. \& CUBEY, R. (2019). Conservation hedges: modern-day arks. Sibbaldia, 17: 71-100. doi: https://doi.org/10.24823/Sibbaldia.2019.268

GARDNER, M., CHRISTIAN, T. \& LUSCOMBE, D. (2017). Tree of the Year: Prumnopitys andina. International Dendrology Society Yearbook 2017, pp. 24-45. Available online: http://www. dendrology.org/publications/tree-of-the-year/ prumnopitys-andina/ (accessed May 2021).

HECHENLEITNER, V.P. (2005). A changing role for the arboretum of the Universidad Austral de Chile (UACH). Sibbaldia, 3: 7-16. doi: https://doi. org/10.24823/Sibbaldia.2005.107

HECHENLEITNER, V.P., GARDNER, M.F., THOMAS, P.I., ECHEVERRÍA, C., ESCOBAR, B., BROWNLESS, P. \& MARTÍNEZ, C. (2005). Plantas Amenazadas del Centro-Sur de Chile. Distribución, Conservación y Propagación. Universidad Austral de Chile, Valdivia, and RBGE, Edinburgh.

KENDRICK, R.C. (2017). Milionia zonea 橙帶藍尺蛾 in Hong Kong. Hong Kong Moths 
(blog). Available online: https://hkmothsblog. wordpress.com/2017/05/20/milionia-zonea-inhong-kong (accessed April 2021).

PAGE, C.N. (1994). The ex situ conservation of temperate rain-forest conifer tree species: a Britishbased programme. Biodiversity Conservation, 3: 191-199. doi: https://doi.org/10.1007/BF02291889

PERTH \& KINROSS COUNTRYSIDE TRUST (2020a). Perthshire Conifer Conservation Programme. Available online: www.pkct.org/pages/category/ pbtc-conifer-conservation-programme (accessed April 2021).

\section{PERTH \& KINROSS COUNTRYSIDE TRUST}

(2020b). National Tree Collections of Scotland. Available online: www.pkct.org/national-treecollections-of-scotland (accessed April 2021).

ROYAL BOTANIC GARDEN EDINBURGH (2016).

Threatened conifers of the world. Available online: https://threatenedconifers.rbge.org.uk (accessed March 2021). 
